\title{
Porosity formation during atmospheric ice accretion: measurements using micro-computed tomography
}

\section{Letter}

Cite this article: Velandia JS, Diener A, Bansmer S (2021). Porosity formation during atmospheric ice accretion: measurements using micro-computed tomography. Journal of Glaciology 67(266), 1228-1234. https://doi.org/ 10.1017/jog.2021.68

Received: 16 November 2020

Revised: 17 May 2021

Accepted: 19 May 2021

First published online: 14 June 2021

Keywords:

Ice engineering; ice in the atmosphere; ice/ atmosphere interactions

\section{Author for correspondence:}

Juan S. Velandia,

E-mail: j.velandia-rodriguez@tu

braunschweig.de

\section{Juan S. Velandia ${ }^{1,2}$ (D), Alexander Diener ${ }^{3}$ and Stephan Bansmer ${ }^{1,2}$}

${ }^{1}$ Institute of Fluid Mechanics, TU Braunschweig, Hermann-Blenk-Str. 37, Braunschweig, Germany; ${ }^{2}$ Coldsense Technologies GmbH, Hermann-Blenk-Str. 37, Braunschweig, Germany and ${ }^{3}$ Institute for Particle Technology, TU Braunschweig, Volkmaroder Str. 5, Braunschweig, Germany

\begin{abstract}
Atmospheric ice accretion results from the exposure of technical equipment or facilities to cold and humid environments. Supercooled droplets in a cloud can impact an airplane's surface and quickly form an ice layer. The presence of air pockets in such a layer is well known and explains the white appearance of some of the accretions. However, estimation of its porosity values and studies on the pore formation mechanics remain limited. In this study, we performed tests in an icing wind tunnel and scans with micro-computed tomography to address these issues. Here, we show that the accretion has closed porosity below $1 \%$, which is mostly produced by the interaction between a spray-like impact on the water surface. The insights we provide here are important to improve ice accretion modelling techniques and establish a different approach to address the interaction between the cloud and the surfaces exposed to atmospheric icing.
\end{abstract}

\section{Introduction}

Atmospheric ice accretion affects technical equipment and machines used in a plethora of engineering applications. The accumulation of ice can lead to a decrease in security and financial profitability in fields like renewable energy, infrastructure and mobility. Wind turbines reduce their power production during icing conditions (Yirtici and others, 2019), structural damage can appear on communication towers (Wahba and others, 1998) and aircraft and drones need to avoid icing conditions to fly safely (AGARD Working Group 20, 1997). The wide range of applications dealing with icing encounters encourages the study of such a complex phenomenon. Some of the aspects studied in this area include the thickness of the ice and the roughness of its surface because they compromise the aerodynamic performance in engineering applications (Velandia and Bansmer, 2020). The characteristics of this layer depend on the icing conditions of the encounter (Gent and others, 2000). Most of the applications mentioned have to deal with temperatures around $-5^{\circ} \mathrm{C}$, where the type of the accretion is known as glaze ice, while colder temperatures lead to accretions known as rime ice. Depending on both the temperature and the droplet characteristics, the water freezes instantly in dry conditions (rime ice) or has enough time to flow over the surface, where water film dynamics play a role in the freezing process (glaze ice).

The composition of the cloud (in terms of liquid water content, LWC and median volume diameter, MVD) and environmental conditions (air temperature, pressure altitude and relative humidity) are of major importance for macroscopic features of the ice layer and when considering the microscopic development of the accretion process. As the ice accumulates, water droplets impact the exposed surface. The impingement process is relevant to the shape of the accretion because it dictates where most of the mass will be allocated on the surface.

The influence of the surface conditions (wet, dry, cooled, inclined, etc.) is a major topic in the research field of droplet impact. A common aspect of all impingement scenarios, from a single droplet impact to spray-driven phenomena, is the air entrapment due to the collision of the droplets with the surface. The presence of air bubbles between the droplets in the cloud approaching the surface and the substrate suggests that air should also be entrapped in the ice layer formed due to droplet impingement. As will be shown later, these air bubbles can cause ice porosity.

The porosity of ice has received a lot of attention from the geologists and the ice physicist communities. Air bubbles in sea ice were studied by Crabeck and others (2016) employing micro-computed tomography. Obbard and others (2009) scanned sea-ice samples using the same technique and identified three different materials in them: ice, air pockets and brine. Coléou and others (2001) also worked with micro-computed tomography to visualise the microstructure of snow, and Wiese and Schneebeli (2017) used it to study changes of snow microstructure exposed to temperature gradients and mechanical loads. One of the major requirements to study the microstructure of ice probes is a small voxel size. Burr and others (2018) suggested on the basis of error analysis that $30 \mu \mathrm{m}$ voxel size might be too large and can induce a large error in microstructural parameters when analysing polar firn.

Nevertheless, compared to sea ice, snow and polar firn, atmospheric ice accretion on technical application grows on a different timescale (in the order of a few minutes) and therefore 
presents different characteristics (Bansmer, 2020). Studies on this type of accretion have focussed mostly on density measurements, estimation and modelling. Ice density in natural and artificial hailstones was studied by Prodi (1970) using X-ray micrographs. The density of ice accretion on a plastic cylinder with a previously frozen thin ice layer was also studied using this technique. The previously frozen layer served as a reference to estimate density distributions in the ice accretion (Prodi and others, 1986). The same technique was then used by Levi and others (1991) to show that void spaces between feather structures influence the overall density of the samples. Vargas and others (2007) used $3 \mathrm{~mm}$ thick samples to estimate the density of the ice accretion using micro-radiography. His research does not focus on pore characteristics, but the samples clearly show the presence of air inclusions. A picture of a thin glaze ice slice was presented and analysed by AGARD Working Group 20 (1997). This image shows large ice grains and pores that are supposedly produced by the closure of surface roughness elements.

Inspired by the analysis of sea ice, snow and polar firn using micro-computed tomography, this study presents ice porosity measurements of ice samples obtained from an icing wind tunnel (IWT) test. We used the model of an engine nacelle inlet as a test object, which is an aircraft component exposed to icing incidents. Ice samples produced on the test object were scanned using an improved cooling device for the micro-computed tomography measurements. We related the porosity of the sample to aerodynamic conditions of the test model and estimated the type of droplet-surface interaction that produces the pores. The obtained results are relevant to IWT operators and atmospheric ice accretion modellers, who usually neglect porosity characteristics of the ice layer when modelling the accretion process. Inclusion of this porosity in the modelling can improve the heat transfer calculation, by considering the isolating effect of air pockets and the final shape of the accretion, by adding void random spaces transforming the general shape.

\section{Materials and methods}

Ice samples were generated in the Braunschweig Icing Wind Tunnel (Bansmer and others, 2018). The samples were extracted and scanned using a micro-computed tomography system (XMT) and a cooling device to keep the ice cold during the scan. The impact conditions of the incoming droplets were observed using a shadowgraphy system. In this section, the experimental approach is presented.

\section{Icing wind tunnel and ice accretion}

Atmospheric icing encounters were reproduced in the IWT. The test model used in this study represents a one-fifth scaled engine nacelle inlet during take-off and climb configurations (Velandia and Bansmer, 2019). The simplified model is a bi-dimensional test object. Bansmer and others (2018) provide a spatial calibration of the IWT test section, which proves a uniform distribution of the cloud characteristics. They also explain the droplet generation mechanism, where water is pressurised and injected into an array of industrial two-stage spray nozzle. A sketch of the set-up in the test section of the IWT is shown in Figure 1a. The flow deflection elements produced flow conditions similar to real flight conditions. As the cloud reached the test section, it froze over the model. The size of the droplets (MVD), the amount of water in the cloud (LWC), the temperature of the flow and the air bubble inclusion controlled the shape and characteristics of the ice accretion. The icing conditions, including the Reynolds number based on the chord of the profile $\left(R e_{c}\right)$ used in this study and a

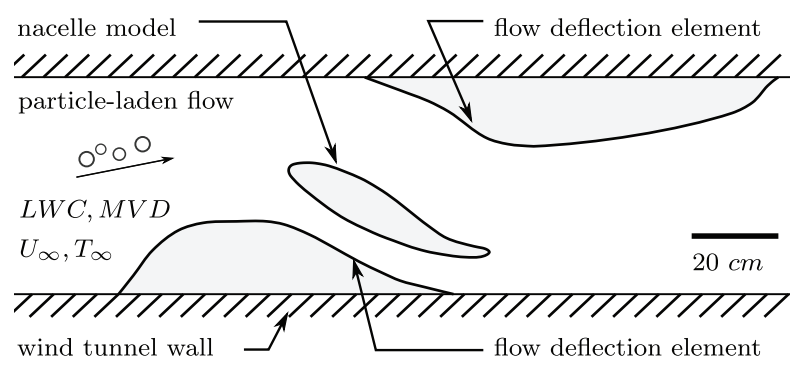

b

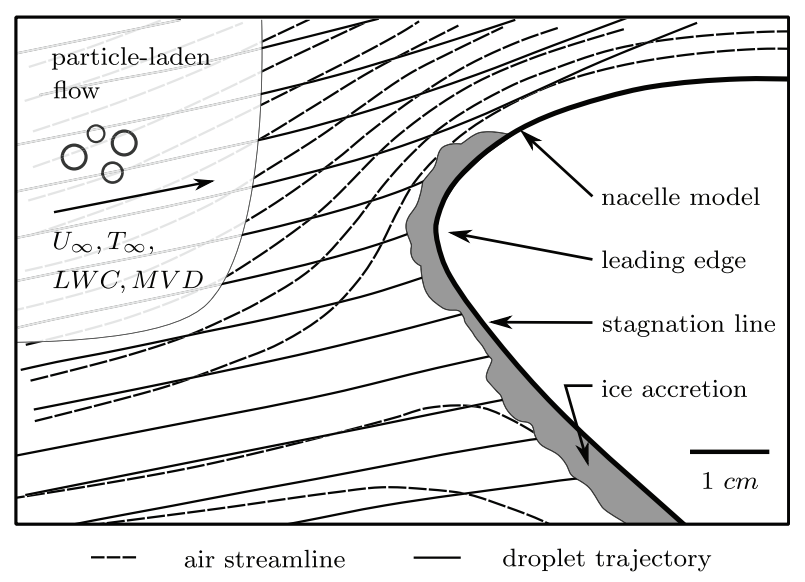

Fig. 1. IWT test section with the test model (a) and a schematic of the flow accretion on the front of the model (b).

the freezing fraction in the stagnation line $\left(\eta_{0}\right)$ (Bond and Anderson, 2004), are summarised in Table 1.

Figure $1 \mathrm{~b}$ presents a scheme of the accretion process. The model was exposed to icing conditions for $8 \mathrm{~min}$. At the end of each test, the thickness of the ice was $\sim 2 \mathrm{~cm}$ in the leading edge zone. Ice samples were taken from the stagnation line and the leading edge of the model. The stagnation line presents the larger aerodynamic pressure in the model and the smoothest region on the accretion, which can affect the formation of the pores.

\section{Extraction and scanning}

The icing event finished when the icing cloud was turned off. The air continues to flow over the model for a short time to wash out the remaining water on the surface. The temperature in the test section is set to $-15^{\circ} \mathrm{C}$ to preserve the internal structure of the ice layer. After some minutes, the iced nacelle model was taken to a climate chamber, where the temperature was set to $-15^{\circ} \mathrm{C}$. A total of 17 ice samples were cut from the accretion layer using a saw. Eight samples were taken from the stagnation line and nine from the leading edge. The size of the samples was $\sim 2 \times 2 \times 10 \mathrm{~mm}^{3}$, as shown in Figure 2 . This size was chosen considering the ice thickness after each run. A cooling box was used to store the samples and transport them to the location of the XMT. The temperature in the cooling box was monitored and kept under $-15^{\circ} \mathrm{C}$ during the transport. The temperature in the XMT room was $21^{\circ} \mathrm{C}$. A cooling device was constructed and used to keep the samples cold (below $0^{\circ} \mathrm{C}$ ) during the scanning process. The device has two peltier elements (in a cascade set up) to cool down a copper stand. The high temperature on the opposite side of the peltier elements is controlled using a microcooler for computer processors cooling. The cooling is enhanced 
Table 1. Icing conditions

\begin{tabular}{ll}
\hline Parameter & Value \\
\hline Velocity $\left(\mathrm{m} \mathrm{s}^{-1}\right)$ & 50 \\
Temperature $\left({ }^{\circ} \mathrm{C}\right)$ & -4.5 \\
LWC $\left(\mathrm{g} \mathrm{m}^{-3}\right)$ & 0.34 \\
MVD $(\mu \mathrm{m})$ & 35.1 \\
$\operatorname{Time}(\mathrm{s})$ & 480 \\
$\operatorname{Re}_{\mathrm{c}}(-)$ & $2 \times 10^{6}$ \\
$\eta_{\mathrm{0}}(-)$ & 0.423 \\
\hline
\end{tabular}

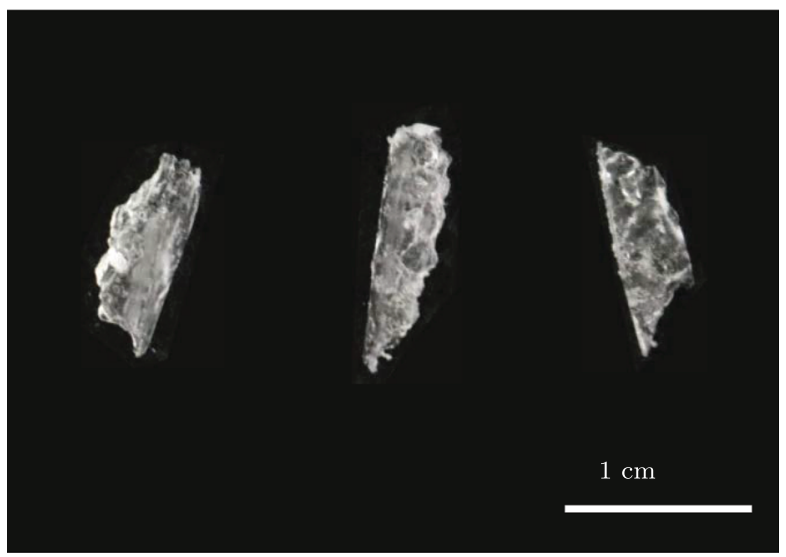

Fig. 2. Ice samples cut from the ice accretion.

with a water cooling circuit, which transports the extracted heat out of the XMT system. The ice samples are located on top of the cold copper stand. A sample holder $(5 \mathrm{~mm}$ diameter, 12 $\mathrm{mm}$ height and $0.5 \mathrm{~mm}$ wall thickness) is fixed at this location. The material of the holder was carefully selected and represents an improvement for this type of cooling device. An innovative approach was taken by using boron nitride to build the holder. The boron nitride does not affect the X-ray image quality because it has a low X-ray absorption coefficient, which is an important characteristic for this type of scan. Furthermore, its large thermal conductivity creates a cold environment around the ice sample. The holder is closed with an isolating cover on top of it to reduce heat and mass exchange with the environment. The whole cooling device is placed on the XMT rotating platform, to produce images from different angles. Wires and water hoses were tied and driven out of the XMT. The water cooling and power supply systems were located next to the scanner. The device was turned on for $30 \mathrm{~min}$ before running the scans. The temperature inside the boron nitride container was set to $-15^{\circ} \mathrm{C}$. After $20 \mathrm{~min}$, the desired temperature was reached. A sketch of the used device with some elements of the XMT system is shown in Figure 3.

The samples were scanned a using high-resolution microcomputed tomography device (MicroXCT-400, Zeiss [Xradia], Germany). The system uses a common set up (Landis and Keane, 2010) where an X-ray source produces a beam, which radiates through the ice sample. The sample is mounted on a rotating platform, which allows us to scan it from different angles. The ice sample absorbs some of the radiation, which is afterwards transformed to a radiography image at the detector. The radiography is transformed to visible light by a scintillator and finally captured by a CCD-detector. Using a back-filtered projection algorithm, the captured slices are converted to stacked images, which result in a 3-D reconstruction of the ice sample. The set-up of the $\mathrm{XMT}$ is summarised in Table 2. On the one hand, scanning ice samples is a time-critical operation due to the risk of melting. On the other hand, there is a trade-off between scanning time

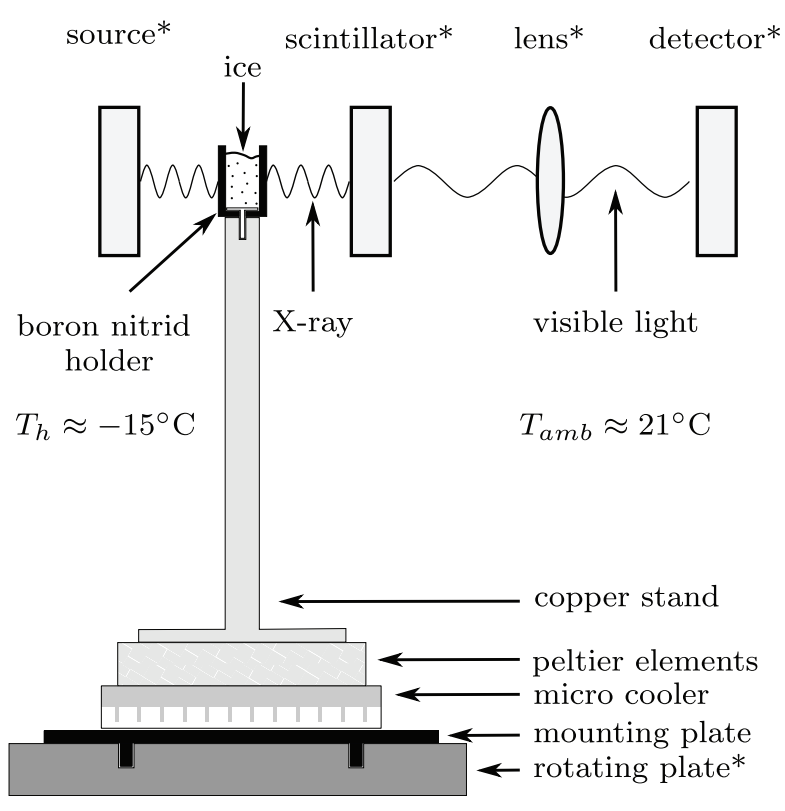

Fig. 3. Scheme of the cooling device in the XMT. Elements marked with an asterisk $\left(^{\star}\right)$ are part of the XMT. $T_{\mathrm{h}}$ is the temperature inside the holder and $T_{\mathrm{amb}}$ the ambient temperature in the room.

Table 2. MicroXCT-400 set up

\begin{tabular}{ll}
\hline Source & \multicolumn{1}{c}{ Detector } \\
\hline Voltage: $40 \mathrm{kV}$ & Objective: $4 \times$ \\
Current: $200 \mu \mathrm{A}$ & Camera binning: 4 \\
Power: $8 \mathrm{~W}$ & Exposure time: $1 \mathrm{~s}$ \\
\hline
\end{tabular}

and resolution. The resolution of our measurements is 7.067 $\mu \mathrm{m} \mathrm{px}^{-1}$. This resolution is only achieved by reducing the distance between the source and the detector in the equipment, thus keeping the size of the samples small. The scanning process produced a set of 2-D horizontal slices of the ice sample. The postprocessing of the scans followed a common procedure used to estimate the porosity from X-ray imaging. A volume of interest (VOI) with a height of $1.5 \mathrm{~mm}$ was extracted from the scanned data. The images were filtered using a non-local means filter (Buades and others, 2005) algorithm with a search window size, local neighbourhood size and similarity value of $18 \mathrm{px}^{2}, 3 \mathrm{px}^{2}$ and 1.5. After filtering, the 2-D images were first segmented and then stacked to reconstruct the 3-D volume. Voxels were marked as ice or air, depending on their intensity value. Isosurfaces in the VOI were extracted and treated as individual pores. All individual pores smaller than a $3 \times 3 \times 3 \mathrm{px}^{3}$ volume were discarded and ignored. The porosity $(\phi)$ of the sample was estimated by the ratio of the air-marked voxels $\left(V_{\mathrm{a}}\right)$ to the volume of the VOI $\left(V_{\mathrm{t}}\right)$ :

$$
\phi=\frac{V_{\mathrm{a}}}{V_{\mathrm{t}}}
$$

\section{Droplet imaging}

Ice accretion is the process in which water droplets impact and freeze on an exposed surface, which in our experimental set-up was the surface of the model. This process is influenced by atmospheric local conditions and cloud characteristics simulated in the IWT. To relate the porosity results to the accretion process, a clearer view of the impingement conditions on the leading edge and the stagnation point was needed. Therefore, a shadowgraphy 
set-up was used in the IWT to observe the droplet size and velocity prior to impingement on the iced surface. The system was composed of a light source (double-pulsed $\mathrm{Nd}$ :YAG laser) and a high-resolution camera. The two elements were aligned in a way that the shadow of the flying droplets is captured by the camera. This set-up allowed us to measure the diameter of the droplets and the change in the position of the droplet at short time intervals $(5 \mu \mathrm{s})$. This measurement provides information about the size of the impingement droplet, its velocity and the angle of impact on the ice layer.

\section{Results and discussion}

This section shows the results of the porosity measurements of atmospheric icing using micro-computed tomography. First, we describe the obtained results. Second, we explain the local icing conditions of the two-sample location. The section finishes with a comparison of possible origins of the porosity found during the measurements.

\section{Porosity characteristics of atmospheric ice}

Figure 4 presents a reconstruction of the scan of two samples, one from the leading edge (sample 0) and one from the stagnation point (sample I). These reconstructions show the ice sample produced during the extraction process as well as its internal structures. The porosity of all samples is $<1 \%$, which, according to percolation theory, implies that it is impossible to form channels between the pores. The representation of the samples in Figure 4 confirms this theory since no channels are observed. This means that the airflow over the ice accretion does not penetrate the ice layer, which is an important result for aerodynamic numerical simulations because it simplifies the treatment of the ice geometry as a closed surface. The sample location and the porosity are displayed in Table 3. The mean porosity for each location $(0.319 \%$ for the leading edge and $0.537 \%$ for the stagnation line) suggests that the porosity is higher in the stagnation line than in the leading edge. We conducted a $t$-test to prove that the difference in the porosity between the two locations is statistically significant (Student, 1908). The test considered the number of samples, the mean value, the standard deviation $(0.134 \%$ for the leading edge and $0.258 \%$ for the stagnation line) and a confidence interval of $95 \%$. Under these conditions, the higher porosity in the stagnation line was confirmed. The pore diameter distribution, presented in Figure 5, provides additional information about the ice. This plot also shows the resolution limit and cumulative porosity. The pore size distribution for both locations is similar and follows a log-normal distribution presented by the black bold line in the figure. The resolution limit of our measurements is indicated by the striped bar. Even though we were not able to capture the smallest pores in the samples, the cumulative porosity proves that the contribution of these pores to the overall porosity of the samples is negligible and that increasing the resolution of the measurements would not have an impact on the overall porosity estimation. On the other side of the cumulative porosity curve (for an equivalent diameter $>150 \mu \mathrm{m}$ ) the steep behaviour in the curve suggests that a single sample does not capture enough pores to be representative. This issue is overcome by scanning several samples on each position.

Table 4 shows the mean pore diameter, median pore diameter and MVD from the pores distributions and the IWT cloud droplets. The median pore diameter lies at around $37.9 \mu \mathrm{m}$ for the stagnation line and around $33.1 \mu \mathrm{m}$ for the leading edge. These values are in the same order of magnitude of the size of the droplets of the wind tunnel cloud, which is expected when a spray impacts a water surface according to Kalantri and others (2006).
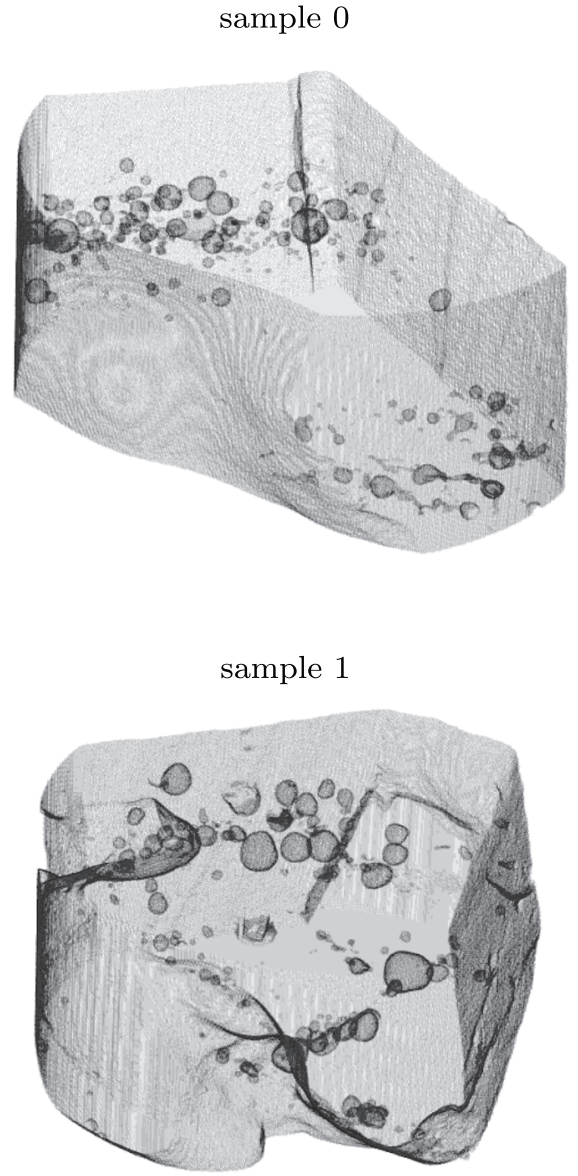

Fig. 4. Tomographic reconstruction of samples from the leading edge (sample 0 ) and the stagnation line (sample 1).

Table 3. Location and porosity of each sample

\begin{tabular}{lcc}
\hline Sample & Location & Porosity $(\phi)(\%)$ \\
\hline 0 & LE & 0.538 \\
I & SP & 0.722 \\
II & LE & 0.147 \\
III & SP & 0.348 \\
IV & LE & 0.481 \\
V & LE & 0.224 \\
VI & SP & 0.523 \\
VII & LE & 0.206 \\
VIII & LE & 0.338 \\
IX & LE & 0.298 \\
X & SP & 0.296 \\
XI & SP & 0.155 \\
XII & SP & 0.559 \\
XIII & LE & 0.310 \\
XIV & SP & 0.902 \\
XV & LE & 0.341 \\
XVI & SP & 0.792 \\
\hline
\end{tabular}

Nevertheless, large discrepancies appear in the mean volume diameter, which are produced by the presence of large pores.

\section{Local impact conditions}

We compared the impact conditions on the leading edge and the stagnation line using the results of the shadowgraphy approach. Figure 6a shows an example of the images used to estimate the droplet impact conditions. The figure shows only a few droplets because the field depth of the set-up is $<2 \mathrm{~mm}$ and droplets out 

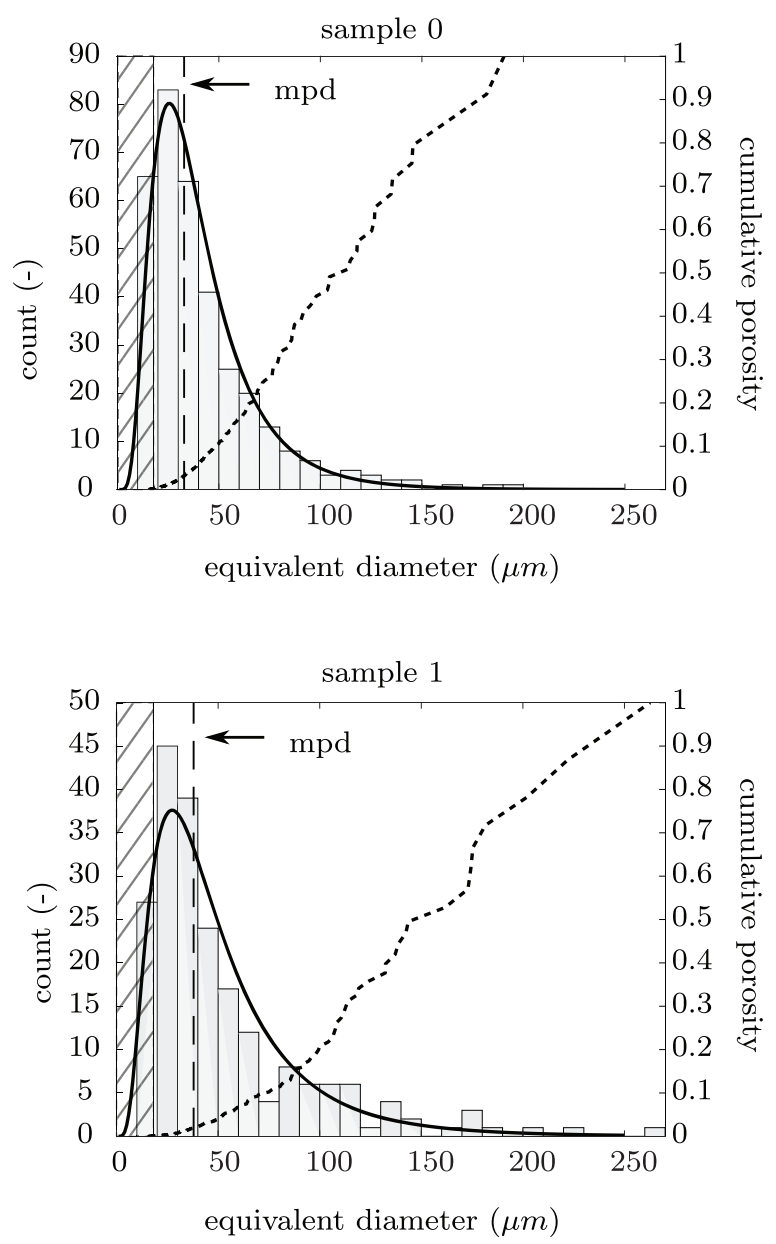

Fig. 5. Pore size distribution, cumulative porosity for samples (discontinuous line), median pore diameter (mpd) and resolution limit (striped region) from the leading edge (sample 0) and the stagnation line (sample 1).

Table 4. Comparison of mean diameter, median diameter and MVD for cloud conditions and two ice samples

\begin{tabular}{lccc}
\hline Statistic & IWT cloud & Sample 0 & Sample 1 \\
\hline Mean diameter $(\mu \mathrm{m})$ & 24.3 & 42.8 & 52.9 \\
Median diameter $(\mu \mathrm{m})$ & 23.5 & 33.1 & 37.9 \\
Mean volume diameter $(\mu \mathrm{m})$ & 35.1 & 109 & 143 \\
\hline
\end{tabular}

of the focal plane cannot be detected. The time interval between the two positions of the droplet is $5 \mu \mathrm{s}$. We estimated the velocity and the angle of impingement on the surface using the distance travelled by the droplet during this time and its trajectory. We considered a droplet with a $32 \mu \mathrm{m}$ diameter for the leading edge and a droplet with a $50 \mu \mathrm{m}$ diameter as a representative droplet for the stagnation line. The velocities obtained were 37.4 and $37 \mathrm{~m} \mathrm{~s}^{-1}$, respectively. We estimated $20^{\circ}$ and $22.2^{\circ}$ impingement angles at both locations. The velocity and the angle of impact suggest that the local droplet impact conditions are similar in both positions, which is in agreement with the similarity in the pore size distribution presented in Figure 5.

We calculated the number of droplets in $1 \mathrm{~cm}^{3}$ about to impact the surface of the model, taking into account the LWC of the icing cloud and the mean volume diameter of the droplets in it. A droplet with a diameter equivalent to the MVD of the cloud $(40 \mu \mathrm{m})$ would have a mass of $3.35 \times 10^{-8} \mathrm{~g}$. An LWC of $0.64 \mathrm{~g} \mathrm{~m}^{-3}$ means that $\sim 18$ droplets would be present in each $\mathrm{cm}^{3}$. Given an airflow velocity of $50 \mathrm{~m} \mathrm{~s}^{-1}, \sim 90000$ droplets impact $1 \mathrm{~cm}^{2}$ each second. This estimation applies for the leading edge and the stagnation line. a

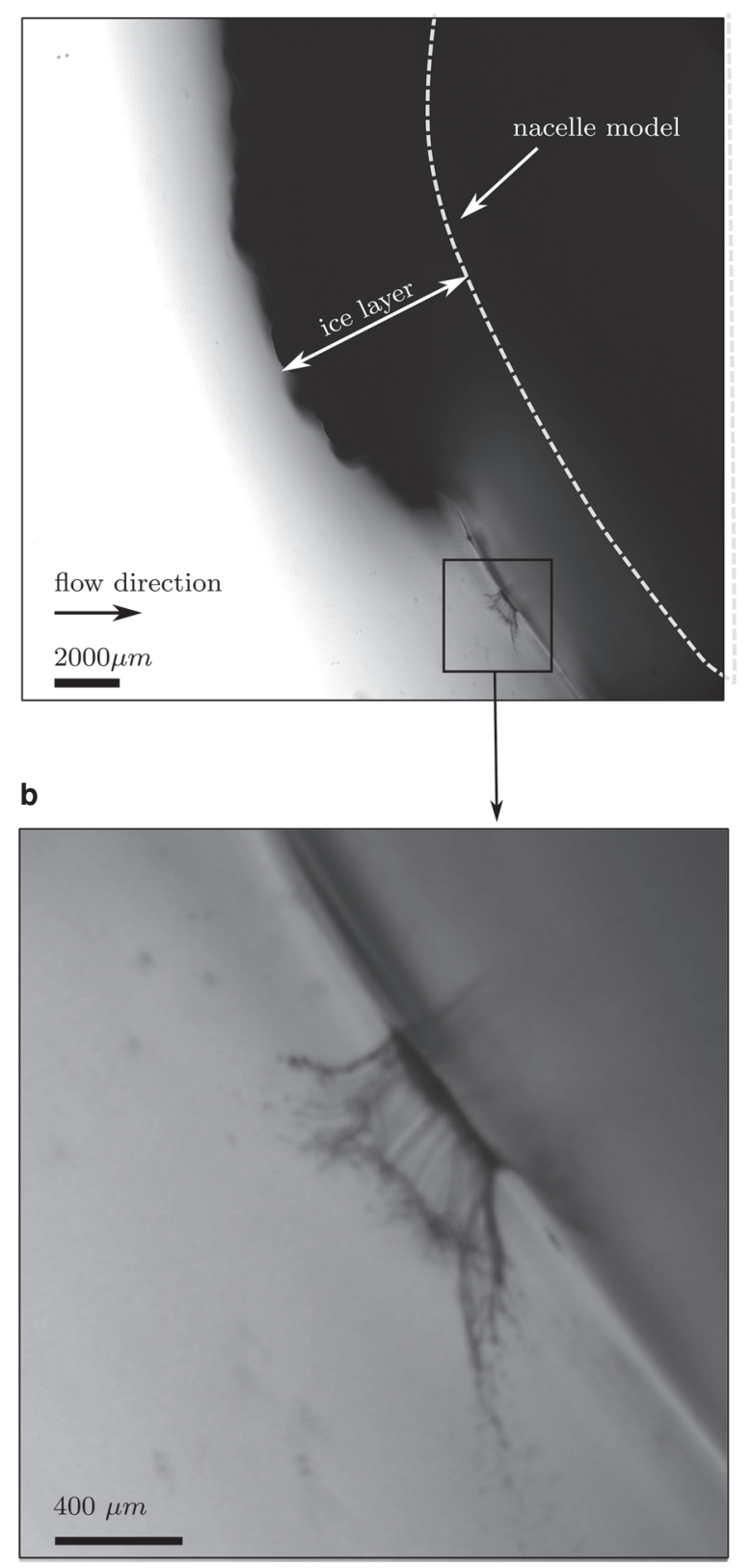

Fig. 6. Visualisation of the ice layer on the model (a) including a corona splash resulting from the impact on a water film (b).

We explained the difference in the porosity estimation between the two locations by addressing the local pressure produced by the flow on the model. Previous investigations showed that the surrounding air pressure plays an important role in promoting or damping the splash upon impact on dry surfaces (Xu and others, 2005). Furthermore, higher ambient pressure reduces the chances of the existing air bubbles leaving the water film after they have formed. By definition, the local pressure on the stagnation point is the highest pressure in the entire model. The local pressure on the leading edge region was estimated to be $5500 \mathrm{~Pa}$ lower than that on the stagnation line. In our findings, larger pressure correlates with larger porosity.

\section{Origin of the pores observed in the samples}

Several processes relating the freezing of water, droplet impact and air entrapment have been studied previously. All of these processes could account for the porosity we found in our 
measurements. The freezing of water over a surface produces the appearance of air bubbles in the frozen structure. The origin of these bubbles is the dissolution of air present in the water. It was shown by Carte (1961) that the size of the bubbles produced by the dissolved air is difficult to estimate because it depends on several factors, including the freezing rate and the amount of dissolved air in the water among others. This mechanism was also observed by Schremb and others (2017), who studied the presence of air inclusions on an impinged supercooled droplet on a dry surface. Nevertheless, our visualisation (Fig. 6b) shows a lamella spreading from the impact location and forming a crown. This is a typical structure of high-speed impacts on wetted surfaces (Burzynski and Bansmer, 2018), demonstrating the presence of water over the ice layer. The impact on the wetted surface causes other types of air entrapment that could explain the size of the pores we found in our samples. Different approaches used to estimate the size of the entrapped bubbles are shown in Table 5 . Droplet impact on wetted surfaces entraps more air than on dry surfaces since the impacting drop interacts with a free interface of the same liquid, promoting cohesion. If the depth of the liquid phase on the surface is large enough, a crater filled with air is formed by the impacting droplet. If not, other air entrapment mechanisms take place, such as the torus-like bubble break. The size of the entrapped bubbles in such impacts has been quantified by several studies. Unfortunately, one of the limitations of our study is that we were not able to estimate the thickness of the water layer to narrow down which kind of interaction is taking place. Most of the related studies deal with a low-speed impingement and larger impacting droplets than the ones used in our experiments. Despite these differences, we can extract trends and rough estimations of the size of the air bubbles produced by the impact of droplets on surfaces.

Thoroddsen and others (2003) reported air bubbles entrapped between the droplet and the water layer with a volume of $2 \%$ of the volume of the impacting droplet. In our case, assuming a droplet of $40 \mu \mathrm{m}$, the entrapped bubbles would have a size of $5.4 \mu \mathrm{m}$. Weiss and Yarin (1999) quantified the size of the bubbles produced by other entrapment mechanisms, such as the torus-like bubble break. In this case, it was estimated that the air bubble radius is $2 \times 10^{-3}$ times the radius of the impacting droplets. For our $40 \mu \mathrm{m}$ droplet, the bubbles would be around $0.1 \mu \mathrm{m}$ in diameter. Hendrix and others (2016) suggested a universal scaling for the ratio between the volume of the impacting droplet and the air bubble depending on the Stokes number of the impacting droplet. According to this scaling, our conditions produce air bubbles with an approximate diameter of $2 \mu \mathrm{m}$. Recently, San Lee and others (2020) suggested a relationship between the impingement velocity and the radius of the entrapped bubble. This results in an air bubble diameter of $0.4 \mu \mathrm{m}$ for a $40 \mathrm{~m} \mathrm{~s}^{-1}$ velocity impact. All the estimated sizes of the air bubbles reported by previous studies are well below the resolution we can achieve with our scanning techniques.

Moreover, the amount of droplets impacting the ice layer (90 $000 \mathrm{~cm}^{-2}$ in $1 \mathrm{~s}$ ) suggests that several droplets impact the surface within a short period of time, which is not the case in the studies mentioned, where one isolated droplet impinges on a wetted surface. This phenomenon is comparable to the impact of a spray on a wetted surface. Kalantri and others (2006) studied this case, showing that the size distribution of the air bubbles entrapped (between 20 and $50 \mu \mathrm{m}$ ) is similar to the droplet distribution produced by the spray (between 30 and $40 \mu \mathrm{m}$ ). Furthermore, the pore size distribution in our samples follows a log-normal distribution, which is commonly observed in the study of atomisers and the characterisation of the droplets forming the spray (Nasr and others, 2002). Given the resolution of our measurements, we were not able to identify pores which might be produced by individual droplet impingement. Nevertheless, the pore size
Table 5. Air bubble diameter $\left(D_{\mathrm{b}}\right)$ from different water impact studies considering air bubble volume $\left(V_{\mathrm{b}}\right)$, impact droplet volume $\left(V_{\mathrm{drop}}\right)$, diameter $\left(D_{\text {drop }}\right)$, radius $\left(R_{\text {drop }}\right)$, Stokes number $(S t)$ and impact velocity $(U)$

\begin{tabular}{llc}
\hline Reference & \multicolumn{1}{c}{ Approach } & $\begin{array}{c}\text { Air bubble } \\
\text { diameter }(\mu \mathrm{m})\end{array}$ \\
\hline Thoroddsen (2003) & $V_{\mathrm{b}}=0.02 * V_{\text {drop }}$ & 5.4 \\
Weiss (1999) & $R_{\mathrm{b}}=2 \times 10^{-3} * R_{\text {drop }}$ & 0.1 \\
Hendrix (2016) & $V_{\mathrm{b}} /\left(2 * V_{\text {drop }}\right) \sim S t^{-4 / 3}$ & 2 \\
San Lee (2020) & $D_{\mathrm{b}}=U^{-0.436}$ & 0.4 \\
Kalantri (2006) & $D_{\mathrm{b}} \approx D_{\text {drop }}$ & 40 \\
\hline
\end{tabular}

distribution and the number of droplets impacting per second suggest that the accumulation of water on the model might be addressed as a spray phenomenon, rather than individual droplet impingement. A spray impact would also change the structure of the water film, creating undulations on the film and thus increasing the amount of air entrapped. These undulations and water film deformation interacting with a rough ice surface could also explain the presence of larger pores, which cannot be directly related to the impact of a spray on a water film.

\section{Conclusions}

This is the first study addressing the porosity and internal structure of atmospheric ice on the scale of a few micrometres. We demonstrated using an IWT and micro-computed tomography measurements that the porosity of the ice accretion in our test conditions lies below $1 \%$. We confirmed the presence of a water film on the ice layer, upon which the droplets from the incoming cloud impacted. The water film, combined with the similitude between the pore size in the samples and the water droplets in the cloud, indicates that their formation process is related to spray-water interaction phenomena.

The accretion process is mostly assumed as droplets impacting independently the surface without interacting with each other. Our measurements suggest that a spray-water interaction also plays a role in the formation of the ice layer. Furthermore, the inclusion of the porosity values and their dependency on local pressure into accretion models, where the effect of porosity tends to be ignored, can improve the prediction accuracy. For aerodynamics applications, our results support the modelling of ice accretions as closed surfaces without considering any flow going through the ice layer.

The study of further icing conditions will enlighten differences in the behaviour of atmospheric ice porosity. For these studies, measuring the water film thickness would be an additional element to analyse the origin of the pores. The estimation of ice density in the samples could be used as a validation method in future studies.

Acknowledgments. The first author is supported by a research grant of the German Academic Exchange Service (DAAD grant no. 57214224). We acknowledge support by the German Research Foundation and the Open Access Publication Funds of the Technische Universität Braunschweig. We want to thank Jan Breitenbach for a fruitful conversation on air entrapment.

\section{References}

AGARD Working Group 20 (1997) Ice accretion simulation. AGARD Advisory report 344, North Atlantic Treaty Organization.

Bansmer S and 9 others (2018) Design, construction and commissioning of the Braunschweig icing wind tunnel. Atmospheric Measurement Techniques 11, 3221-3249. doi: 10.5194/amt-11-3221-201.

Bansmer S (2020) Aircraft Icing: A Challenging Problem of Fluid Mechanics. Göttingen, Germany: Cuvillier Verlag.

Bond T and Anderson D (2004) Manual of scaling methods. Technical Report NASA/CR-2004-212875. 
Buades A, Coll B and Morel J (2005) A non-local algorithm for image denoising. In 2005 IEEE Computer Society Conference on Computer Vision and Pattern Recognition (CVPR'05), volume 2, pp. 60-65.

Burr A, Ballot C, Lhuissier P, Martinerie P, Martin CL and Philip A (2018) Pore morphology of polar firn around closure revealed by X-ray tomography. The Cryosphere 12(7), 2481-2500. doi: 10.5194/tc-12-2481-2018.

Burzynski DA and Bansmer SE (2018) Droplet splashing on thin moving films at high Weber numbers. International Journal of Multiphase Flow 101, 202-211. doi: 10.1016/j.ijmultiphaseflow.2018.01.015.

Carte AE (1961) Air bubbles in ice. Proceedings of the Physical Society 77(3), 757-768. doi: 10.1088/0370-1328/77/3/327.

Coléou C, Lesaffre B, Brzoska J, Ludwig W and Boller E (2001) Three-dimensional snow images by X-ray microtomography. Annals of Glaciology 32, 75-81. doi: 10.3189/172756401781819418.

Crabeck $\mathbf{O}$ and 9 others (2016) Imaging air volume fraction in sea ice using non-destructive X-ray tomography. The Cryosphere 10, 1125-1145. doi: 10. 5194/tc-10-1125-2016.

Gent RW, Dart NP and Cansdale JT (2000) Aircraft icing. Philosophical Transactions of the Royal Society A 358, 2873-2911. doi: 10.1098/rsta. 2000.0689.

Hendrix MHW, Bouwhuis W, van der Meer D, Lohse D and Snoeijer JH (2016) Universal mechanism for air entrainment during liquid impact. Journal of Fluid Mechanics 789, 708-725. doi: 10.1017/jfm.2015.757.

Kalantri D, Roisman I and Tropea C (2006) Spray impact onto deep liquid layers: deformation of air-liquid interface, secondary spray and air bubble entrainment. 10th ICLASS Conference.

Landis E and Keane D (2010) X-ray microtomography. Material Characterization 61, 1305-1316. doi: 10.1016/j.matchar.2010.09.012.

Levi L, Nasello OB and Prodi F (1991) Morphology and density of ice accreted on cylindrical collectors at low values of impaction parameter. I: fixed deposits. Quarterly Journal of the Royal Meteorological Society 117 (500), 761-782. doi: 10.1002/qj.49711750006.

Nasr G, Yule A and Bendig L (2002) Background on Sprays and Their Production. doi: 10.1007/978-1-4471-3816-7.

Obbard R, Troderman G and Baker I (2009) Imaging brine and air inclusions in sea ice using micro-X-ray computed tomography. Journal of Glaciology 55, 1113-1115. doi: 10.3189/002214309790794814.

Prodi F (1970) Measurements of local density in artificial and natural hailstones. Journal of Applied Meteorology 9(6), 903-910. doi: 10.1175/ 1520-0450(1970)009<0903:MOLDIA>2.0.CO;2.
Prodi F, Levi L and Pederzoli P (1986) The density of accreted ice. Quarterly Journal of the Royal Meteorological Society 112(474), 1081-1090. doi: 10. 1002/qj.49711247409.

San Lee J and 6 others (2020) Air evolution during drop impact on liquid pool. Scientific Reports 10(1), 1-10.

Schremb M, Roisman IV and Tropea C (2017) Transient effects in ice nucleation of a water drop impacting onto a cold substrate. Physical Review E 95, 022805. doi: 10.1103/PhysRevE.95.022805.

Student (1908) The probable error of a mean. Biometrika 6(1), 1-25. doi: 10 2307/2331554.

Thoroddsen ST, Etoh TG and Takehara K (2003) Air entrapment under an impacting drop. Journal of Fluid Mechanics 478, 125-134. doi: 10.1017/ S0022112002003427.

Vargas M, Broughton H, Sims J, Bleeze B and Gaines V (2007) Local and total density measurements in ice shapes. Journal of Aircraft 44(3), 780 789. doi: $10.2514 / 1.23326$.

Velandia J and Bansmer S (2019) Topographic study of the ice accretion roughness on a generic aero-engine intake. In 2019 AIAA Aerospace Sciences Meeting. doi: 10.2514/6.2019-1451.

Velandia JS and Bansmer SE (2020) Detailed atmospheric ice accretion surface measurement using micro-computed tomography. Atmospheric Science Letters 21(10), e997. doi: 10.1002/asl.997.

Wahba YM, Madugula MK and Monforton GR (1998) Effect of icing on the free vibration of guyed antenna towers. Atmospheric Research 46 (1), 27-35. doi: https://doi.org/10.1016/S0169-8095(97)00048-3.

Weiss DA and Yarin AL (1999) Single drop impact onto liquid films: neck distortion, jetting, tiny bubble entrainment, and crown formation. Journal of Fluid Mechanics 385, 229-254. doi: 10.1017/S002211209800411X.

Wiese $\mathbf{M}$ and Schneebeli $\mathbf{M}$ (2017) Snowbreeder 5: a micro-CT device for measuring the snow-microstructure evolution under the simultaneous influence of a temperature gradient and compaction. Journal of Glaciology 63, 355-360. doi: 10.1017/jog.2016.143.

Xu L, Zhang WW and Nagel SR (2005) Drop splashing on a dry smooth surface. Physical Review Letters 94, 184505. doi: 10.1103/PhysRevLett.94. 184505.

Yirtici O, Ozgen S and Tuncer IH (2019) Predictions of ice formations on wind turbine blades and power production losses due to icing. Wind Energy 22(7), 945-958. doi: 10.1002/we.2333. 